\title{
Special issue from the ISPRS 3D-ARCH2011 and 3D-ARCH2013 workshop on "3D virtual reconstruction and visualization of complex architectures"
}

\author{
Fabio Remondino
}

Published online: 5 June 2014

(C) Società Italiana di Fotogrammetria e Topografia (SIFET) 2014

The bi-annual ISPRS Workshop on "3D Virtual Reconstruction and Visualization of Complex Architectures" (http:// www.3d-arch.org) is a series of events focusing on the process of creating virtual environments from multiple data sources. The workshop includes topics like automated 3D modeling algorithms and techniques, procedural methods for architectural modeling, accuracy requirement and assessment for 3D reconstruction, low-cost sensors and open-source algorithms for architecural 3D modeling, algorithms for terrestrial sensors and data integration, automated BIM geometry capture, and so on.

The papers presented in this special issue derive papers from the 2011 and 2013 events which took place in Trento (Italy) and three best paper awards. The articles touches research topics on complex architectures and highlights outstanding methodologies developed in this research field.

Enjoy the reading,

F. Remondino 